\title{
Ground magnetometric surveys and integrated geophysical methods for solid buried waste detection: a case study
}

\author{
Marco Marchetti, Lili Cafarella, Domenico Di Mauro and Achille Zirizzotti \\ Istituto Nazionale di Geofisica e Vulcanologia, Roma, Italy
}

\begin{abstract}
The detection of illegal buried waste by means of geophysical techniques has recently become a major effort in shallow geophysical investigations. In particular, detection and location of underground metallic storage tanks can be accomplished using different instruments and techniques. In this paper we describe the results of an investigation carried out in a tuff quarry in Riano Flaminio (north Rome, Italy). A preliminary magnetometric survey revealed the existence of anomalous zones in the analysed region. Excavation in some of the selected areas confirmed that the anomalies were generated by underground magnetic material: over 160 steel drums were found. After their removal, a new magnetometric survey was performed. On the basis of the new map, a multifrequency induction survey, a geoelectrical profile and GPR measurements were taken to extend the characterization of the subsoil.
\end{abstract}

Key words environmental pollution-geophysical surveys - buried waste - magnetic anomalies

\section{Introduction}

The ever-increasing interest in environmental problems has recently spurred the scientific community to improve geophysical methods aimed at the detection of illegal waste disposal sites. In particular, detection and location of buried steel storage tanks can be done through several geophysical methods (Pierce and De Reamer, 1993; Foley, 1994; Vogelsang, 1995; Gibson et al., 1996; Marchetti et al., 1998). Generally in these cases the magnetic surveys are those most frequently used allowing a quick

Mailing address: Dr. Marco Marchetti, Istituto Nazionale di Geofisica e Vulcanologia, Via di Vigna Murata 605, 00143 Roma, Italy; e-mail: marchettim@ingv.it detection of underground metallic refuse. Typically, such method consists of two different kind of measurements: the total intensity of the local magnetic field and its vertical gradient. Moreover, detection of metallic buried waste using magnetometric surveys is advantageous for the low cost of its non invasive execution, and the rapidity of data collection and progressing. The exploration and localization of hazardous, toxic buried waste with only magnetic signature, depends on the depth of the target and on the material the hidden body is made of, since a nonmagnetic body is completely transparent to detection by this kind of investigation. This limitation can be removed if other techniques such as active electromagnetic, GPR (Ground Penetrating Radar) and geoelectrical methods, based on different physical properties of the inspected matter, are used.

This paper describes different investigation techniques used in an old tuff quarry at Riano Flaminio (north of Rome) where the presence of 
buried toxic waste in the subsoil was suspected by the «Government Waste Recycling Committee». Thanks to the first magnetic investigation, many steel drums were found in some points of the quarry. After a preliminary reclaiming, a multifrequency induction survey, a geoelectrical profile and GPR measurements were carried out in order to characterize the subsoil in the study area.

\section{Magnetic measurements}

Istituto Nazionale di Geofisica e Vulcanologia in Rome has been involved for some years with the Italian Government Waste Recycling Committee (Ufficio di Presidenza della commissione parlamentare d'inchiesta sul ciclo dei rifiuti e sulle attività illecite ad esso connesse) in performing geophysical investigations in order to check the presence in the subsoil of buried toxic waste; one of the latest investigations was undertaken in an old tuff quarry at Riano Flaminio (north of Rome, Central Italy, fig. 1).

As is known, magnetometers can be successfully used to detect ferromagnetic targets because they can measure the superposition of the earth's magnetic field and the induced magnetic field in the targets, that depends on their volume magnetic susceptibility. In this way, local variation in the geomagnetic field can be used to identify and to locate the presence of buried ferromagnetic bodies. Shallow exploration to locate and quantify buried hazardous and toxic waste filled drums with magnetic signature can then be advantageously performed by this kind of survey (for an example of a test site see Marchetti et al., 1998) especially for the low cost and rapidity of collection and data elaboration. Of course the success of magnetometric measurements essentially depends on the depth of the target, since the resolution of potential field data decreases rapidly with distance from the sources and depends on the material a hidden body is

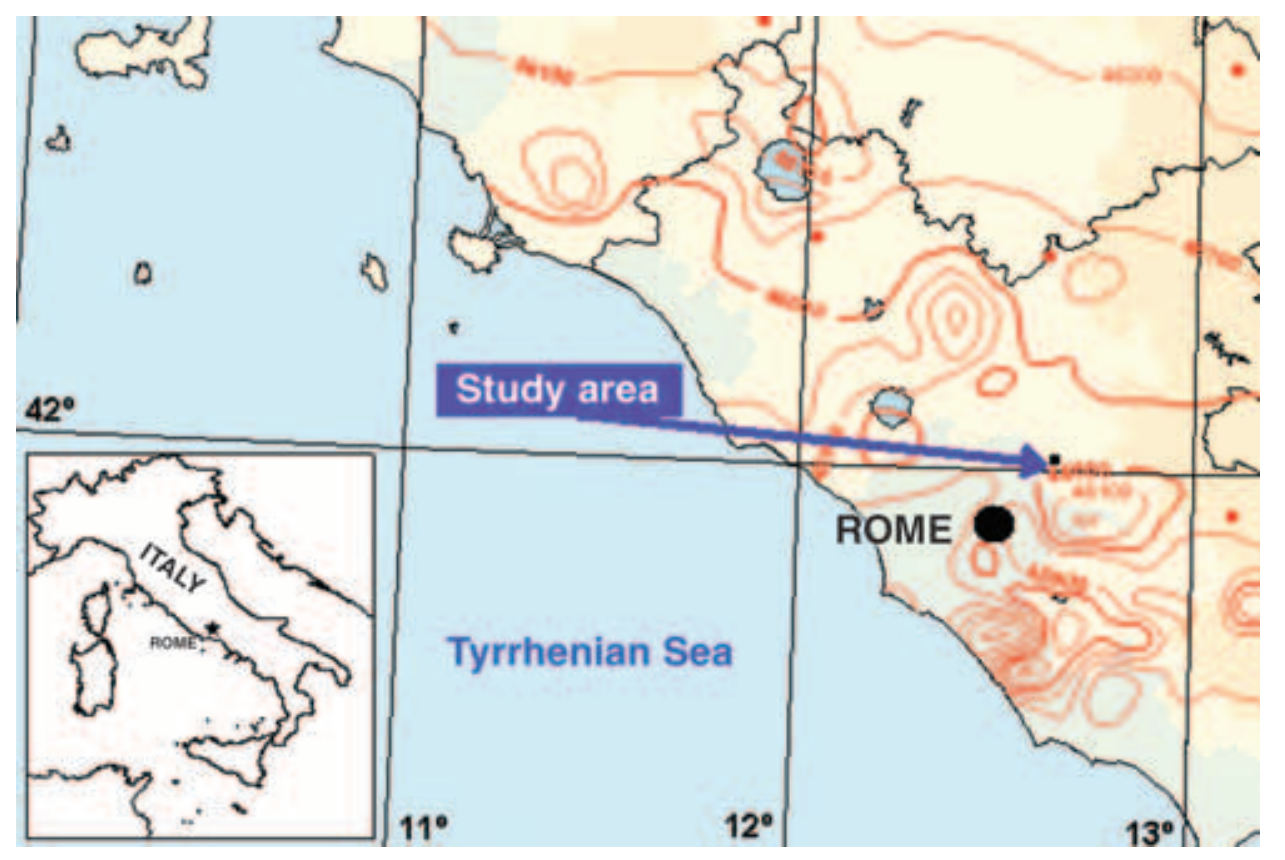

Fig. 1. Location of study area. Riano Flaminio is a small town near Rome (Central Italy). Extracted from the Italian Geomagnetic Total Field map at year 2000.0 (Coticchia et al., 2001). 


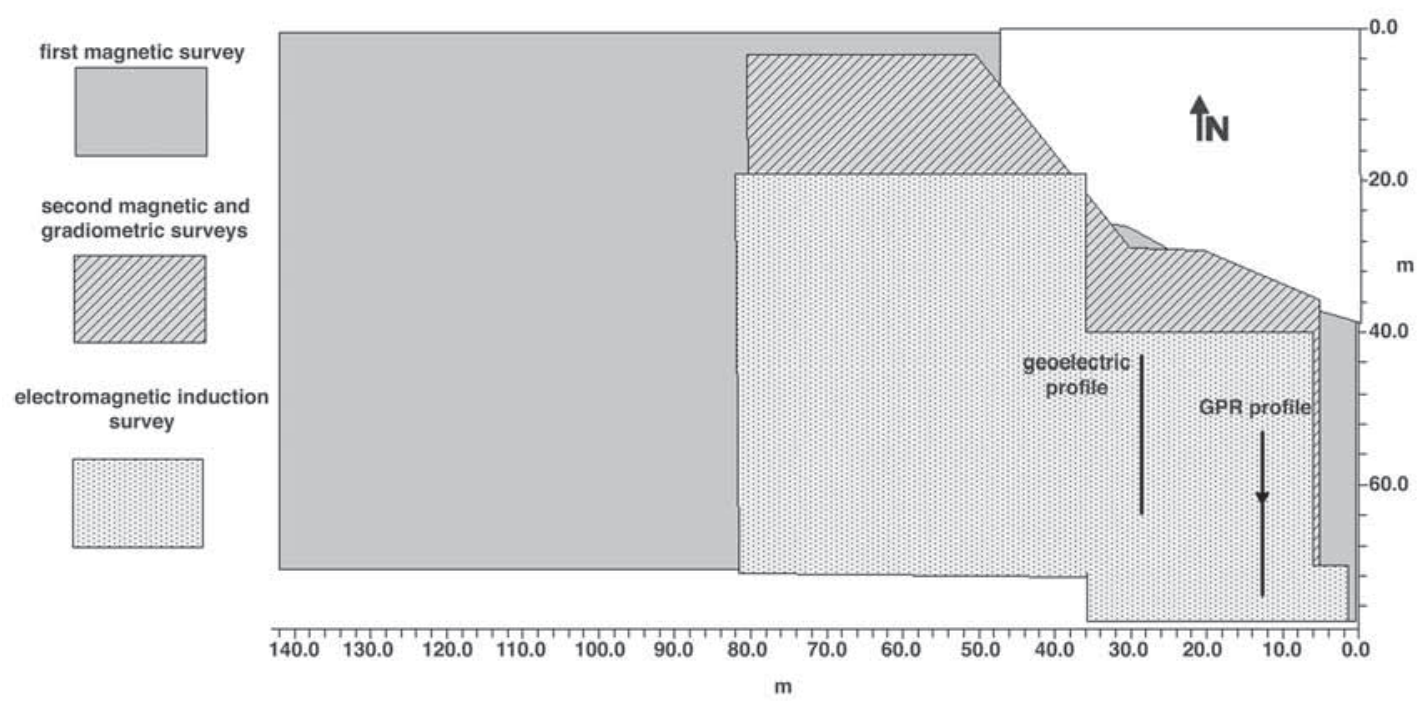

Fig. 2. General scheme of the different geophysical surveys carried out on the whole analysed area.

made of. Other techniques based on different physical properties of the inspected matter are also useful to detect different kind of waste (Gilkeson et al., 1992; Cochran and Dalton, 1995; Dahlin and Jeppsson, 1995).

In order to ascertain the existence and location of underground buried storage tanks in an old quarry (of about $10000 \mathrm{~m}^{2}$ ), a magnetic survey was planned. This area is located at Riano Flaminio, north of Rome (fig. 1). Magnetic data were collected using a Geometrics G-856 proton precession magnetometer. 36 profiles spaced $3 \mathrm{~m}$, with a sampling step of $1 \mathrm{~m}$ along each line were executed. On the whole, about 1500 measurements were made (fig. 2). The diurnal variation of the geomagnetic field and the electromagnetic noise produced by the near railway line were monitored with a second identical magnetometer set close to the area. It was considered a reference station to perform the magnetic data reduction.

Figure 3 shows the map of the magnetic anomalies of the geomagnetic total intensity field. Five anomalous areas clearly emerge: dipolar magnetic anomalies with the main axis N-S oriented, reaching an intensity range of about
1000-1500 nT. They reveal the presence of some ferromagnetic bodies in the subsoil. The diggings up to $4 \mathrm{~m}$ in depth corresponding to the anomalies brought to light over 160 rusty steel drums containing toxic waste, dangerous materials and different kind of refuse (photo 1). The drums were mainly placed in horizontal position, and they have already been recovered at a starting depth of 1.0-1.5 m from ground level.

After a first reclamation of this area, the original morphology was restored. Some months later, a new magnetic survey in the eastern sector was performed using a optical pumped caesium magnetometer, Geometrics mod. G-858. The new survey was carried out along profiles $3 \mathrm{~m}$ apart with a sampling step of $1 \mathrm{~m}$ on a more restriced area of $5600 \mathrm{~m}^{2}$ (fig. 2). The magnetometer was used in the gradiometer configuration (two sensors mounted on a vertical staff at a distance of $0.8 \mathrm{~m}$ apart) in order to measure the vertical gradient of the magnetic field and the intensity of the field.

A new magnetic anomalies map (total field intensity) was drawn and the result is shown in fig. 4a. From the comparison of the new map with the previous one, a strong decrement of anomalies due to the absence of the ferro- 


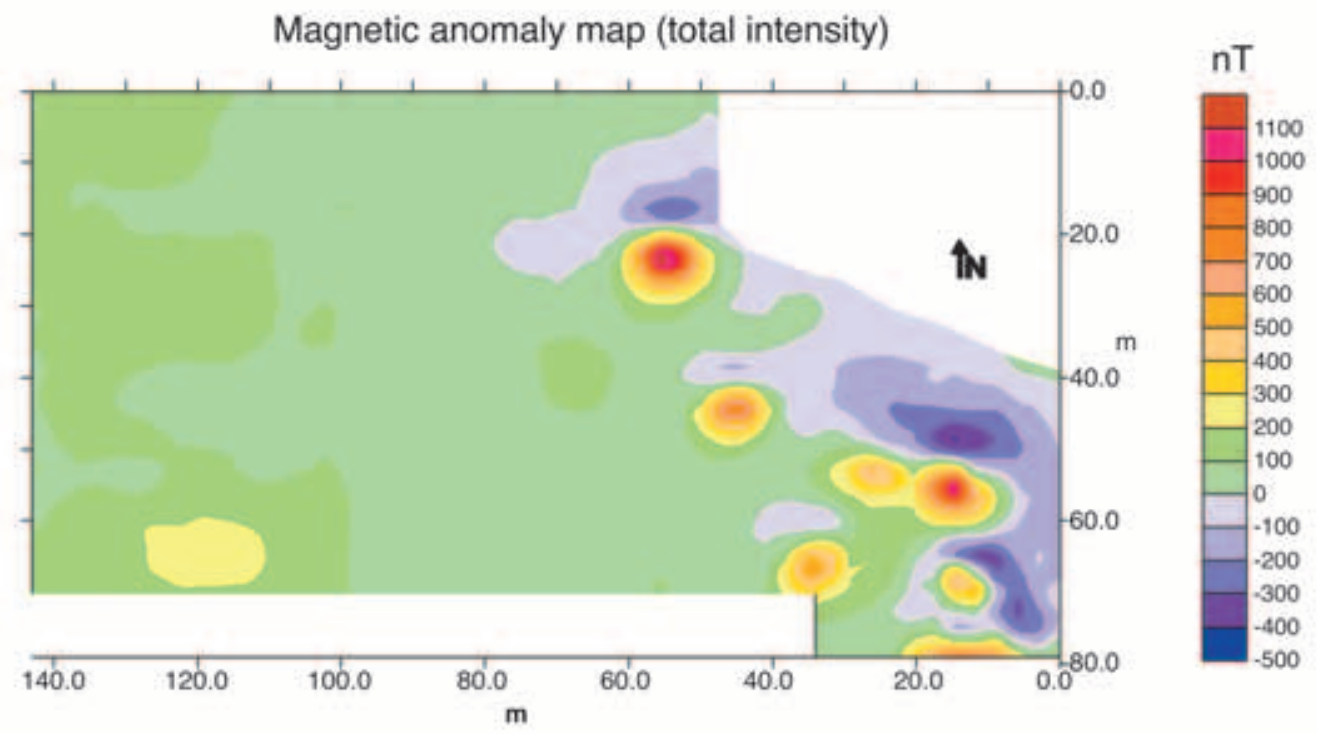

Fig. 3. First map of the magnetic anomalies of the total intensity field on the whole area.

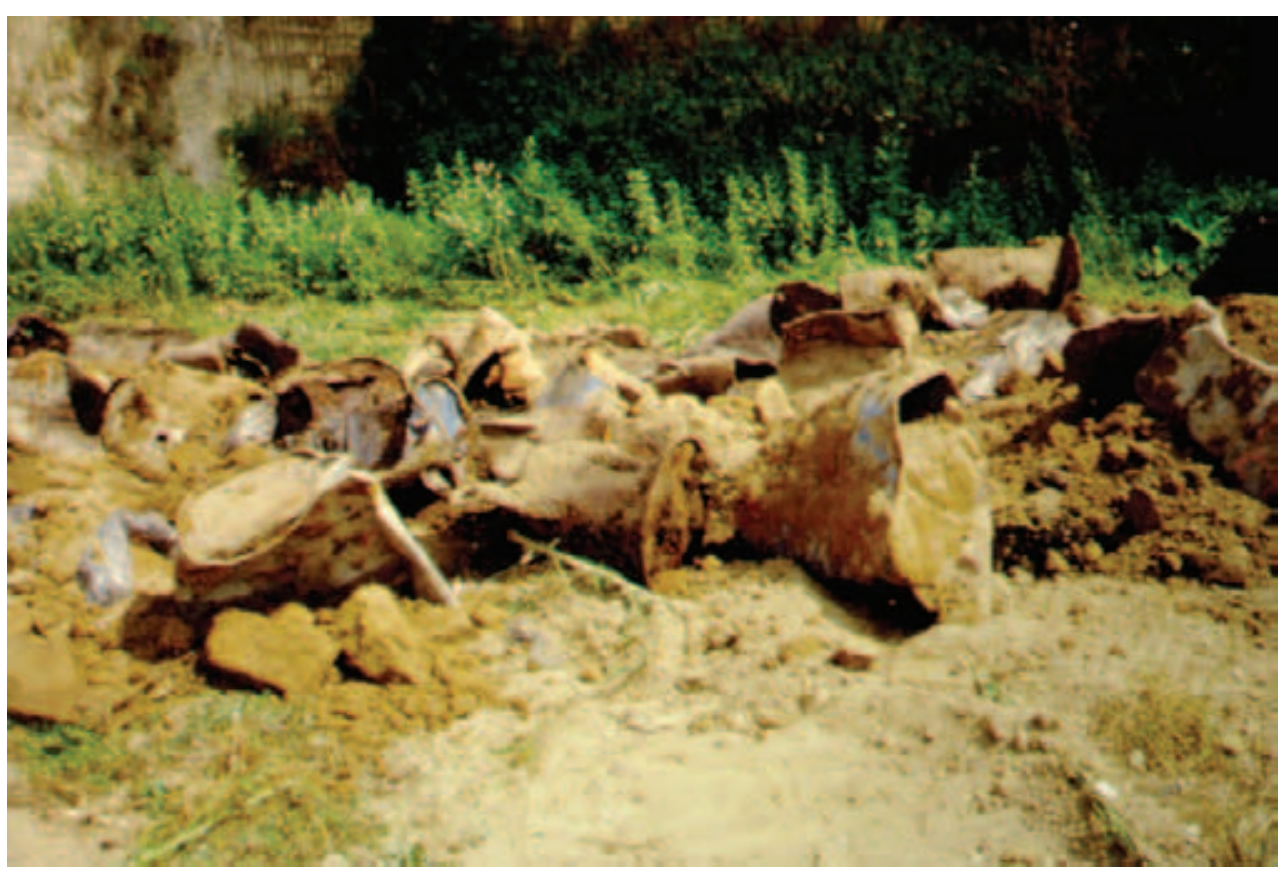

Photo 1. Some steel drums dug out after the first magnetometric survey performed at Riano Flaminio (north of Rome, Italy). 
(a)

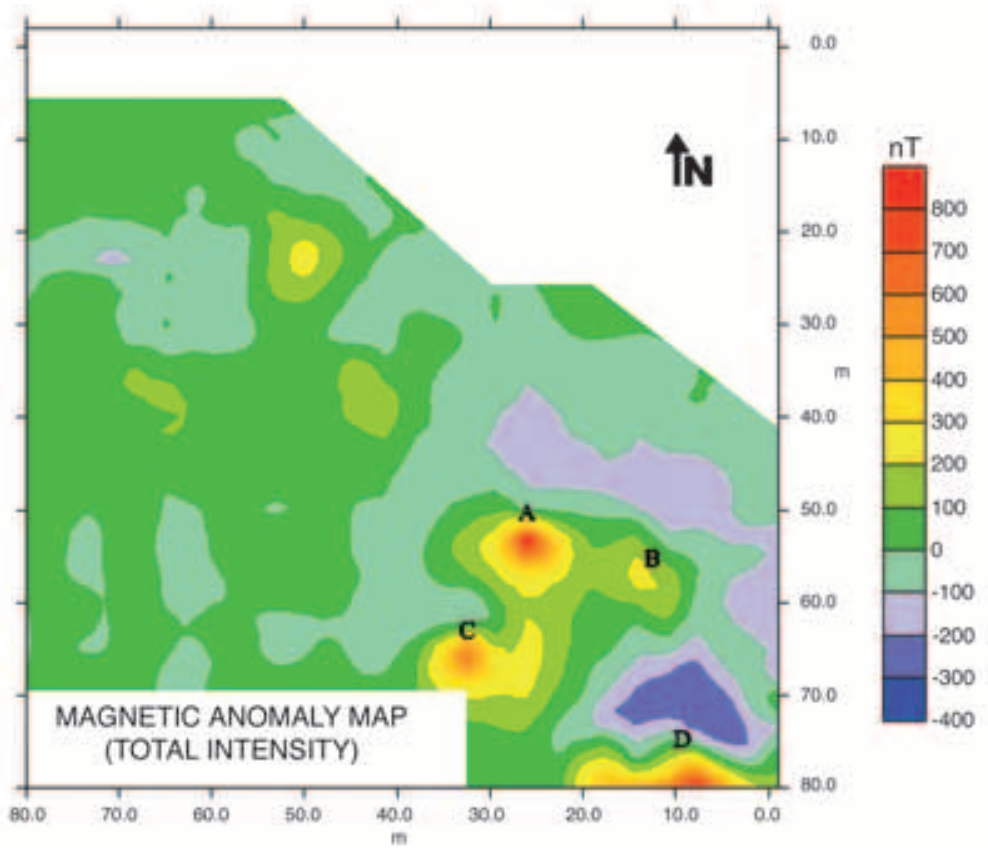

(b)

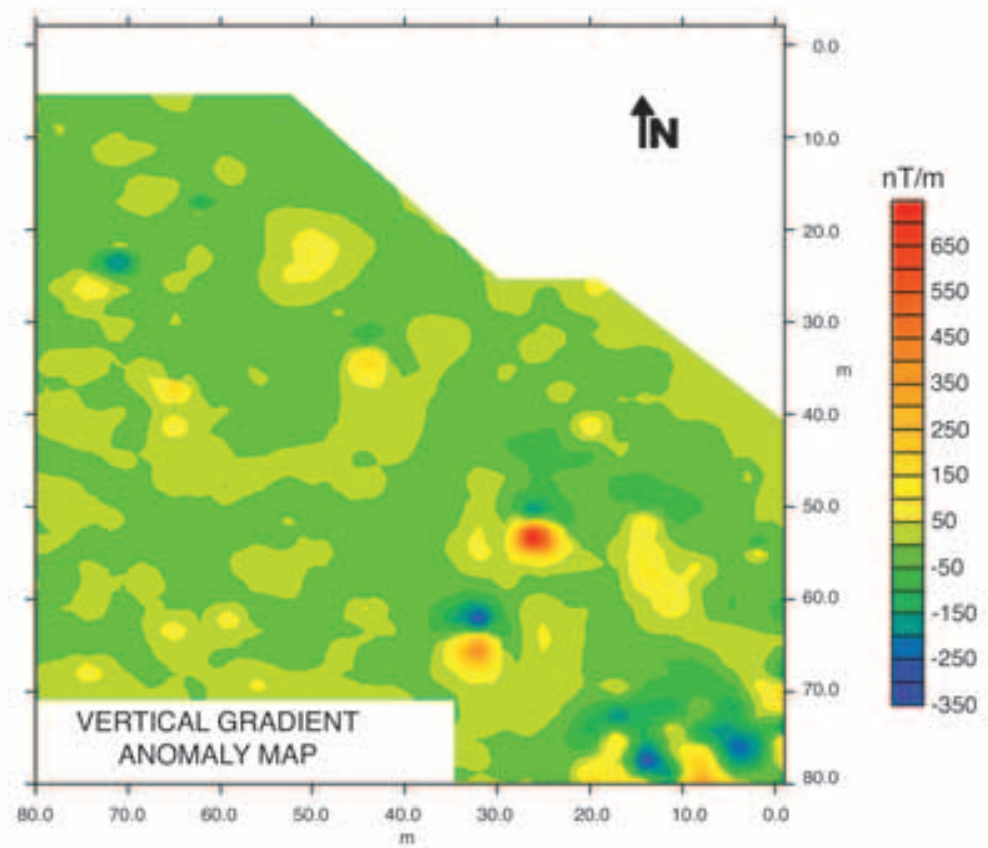

Fig. 4a,b. New magnetic anomaly map of the total intensity field (a) and the magnetic vertical gradient map (b) after the removal of 160 steel drums on the restricted sector (about $5600 \mathrm{~m}^{2}$ ). 
magnetic material removed from the subsoil is clear. On the other hand, some anomalies enhanced, as in the case of the anomaly identified by the letter $\mathrm{A}$ in fig. $4 \mathrm{a}$, where no excavation was made. Anomaly B is reduced to about 380 $\mathrm{nT}$ with respect to the corresponding anomaly in fig. 3. Anomaly $\mathrm{C}$ is about $600 \mathrm{nT}$ while anomaly $\mathrm{D}$ reaches about $1000 \mathrm{nT}$.

The gradient data are especially useful for detecting objects buried at shallow depth (Breiner, 1973). Figure $4 \mathrm{~b}$ also shows the vertical gradient of a sector of the area: this map discloses some details of the anomalies of the geomagnetic field. As a matter of fact, anomalies $\mathrm{A}$ and $\mathrm{C}$ are more evident than in the total intensity map whereas $\mathrm{B}$ and $\mathrm{D}$ are very weak. As we have pointed out before, the deeper a given $3 \mathrm{D}$ source is, the lower the gradient measurements. The differences between the two maps can be explained if we assume that the bodies responsible for the $\mathrm{B}$ and $\mathrm{D}$ anomalies are deeper than the $\mathrm{A}$ and $\mathrm{C}$ ones. In particular D seems to be divided in two parts: this is probably due to the presence in the subsoil of two close masses of ferromagnetic waste. Starting from the vertical gradient and from the anomalies of the total field intensity, we can obtain an approximation of the depth of the sources associated with their anomalies, $z=-3 T /(d T / d z)$, where $T(\mathrm{nT})$ is the geomagnetic intensity and $d T / d z$ the value of the vertical gradient. In our case we estimated a depth, for the ferromagnetic masses, of about 1 and $2 \mathrm{~m}$ for anomalies $\mathrm{A}$ and $\mathrm{C}$ respectively, $4 \mathrm{~m}$ for $\mathrm{B}$ and D. These results confirm our considerations about the depth of the magnetic bodies deduced from a comparison of the maps showed in fig. $4 a, b$.

\section{Electromagnetic induction measurements}

The electromagnetic induction method can detect lateral and vertical variations of electrical conductivity. The method is useful for detection of landfills and buried waste because the electrical conductivity of these materials is greater than the surrounding geologic layers. The instruments used in this kind of survey include a transmitter and a receiver loop. The transmitter generates an alternating magnetic field (primary field) which induces a flow of currents within the earth below. This induced current, in turn, generates a secondary magnetic field detected by the receiver coil. The secondary field is resolved into quadrature and in-phase components against the primary field strength. The ratio between the amplitude of quadrature-component and the primary field depends on the electrical conductivity of the geologic materials. The ratio between the in-phase component and the primary field depends on the resistivity of the material and is more sensitive to metallic materials (Gilkeson et al., 1992).

The electromagnetic survey was performed using GSSI GEM 300 equipment. This instrument works in the frequency domain and can be configured to measure up to 16 user-defined frequencies between $330 \mathrm{~Hz}$ and $20000 \mathrm{~Hz}$. In this way, using different frequencies, it is possible to map the subsurface at different depths. The field detected by the receiver loop is then split into in-phase and quadrature components which are expressed as a percentage intensity of the signal against the primary field strength. This technique also offers the possibility to draw a map whose anomalies are almost monopolar, centred directly above the target giving an easier interpretation of the position than dipolar magnetic anomalies (in which the target is commonly located at the slope of an anomaly, Won et al., 1996).

In our case, the survey was carried out continuously along profiles E-W oriented and at a distance $2 \mathrm{~m}$, using 2010-3210-5010-7950$12570-19950 \mathrm{~Hz}$ frequencies. The results show a good correlation with the results given by magnetic method. In fig. 5a, the in-phase anomaly maps at $19950 \mathrm{~Hz}$ and $5010 \mathrm{~Hz}$ (expressed as a percentage in intensity of the signal), show two monopolar anomalies corresponding to the $\mathrm{A}$ and $\mathrm{C}$ magnetic anomalies. In south direction two separated, electromagnetic monopolar anomalies, close to the single D magnetic anomaly, are shown. This separation, as we referred before, is also visible in the map of the vertical gradient shown in fig. 4b. Similar information emerged from the in-phase maps at different frequencies (not reported here). On the contrary, in these maps the anomaly B is hardly visible, probably due to the presence of a poor amount of buried 


\section{In-Phase}

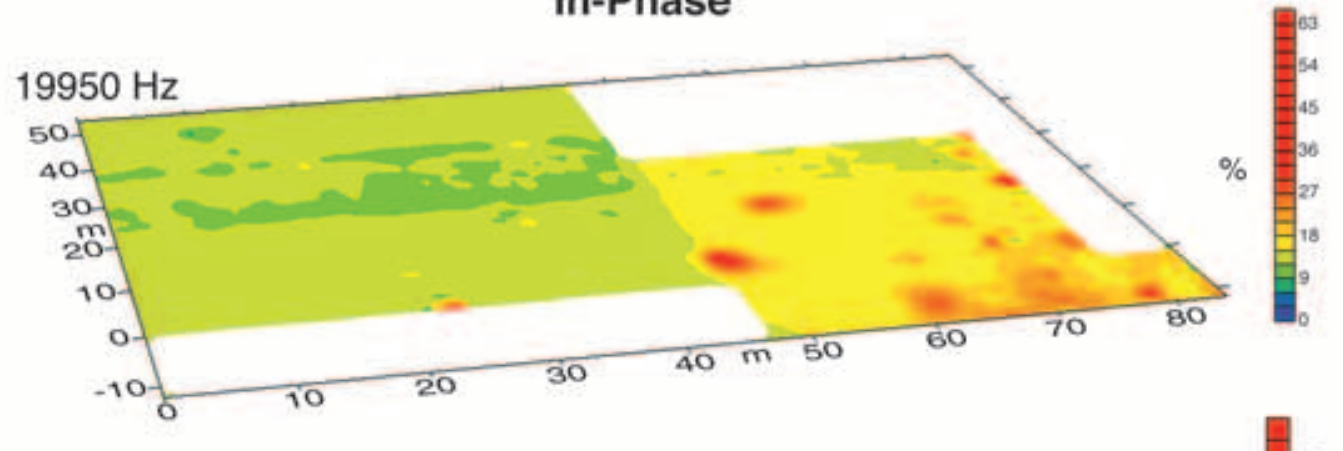

(a)
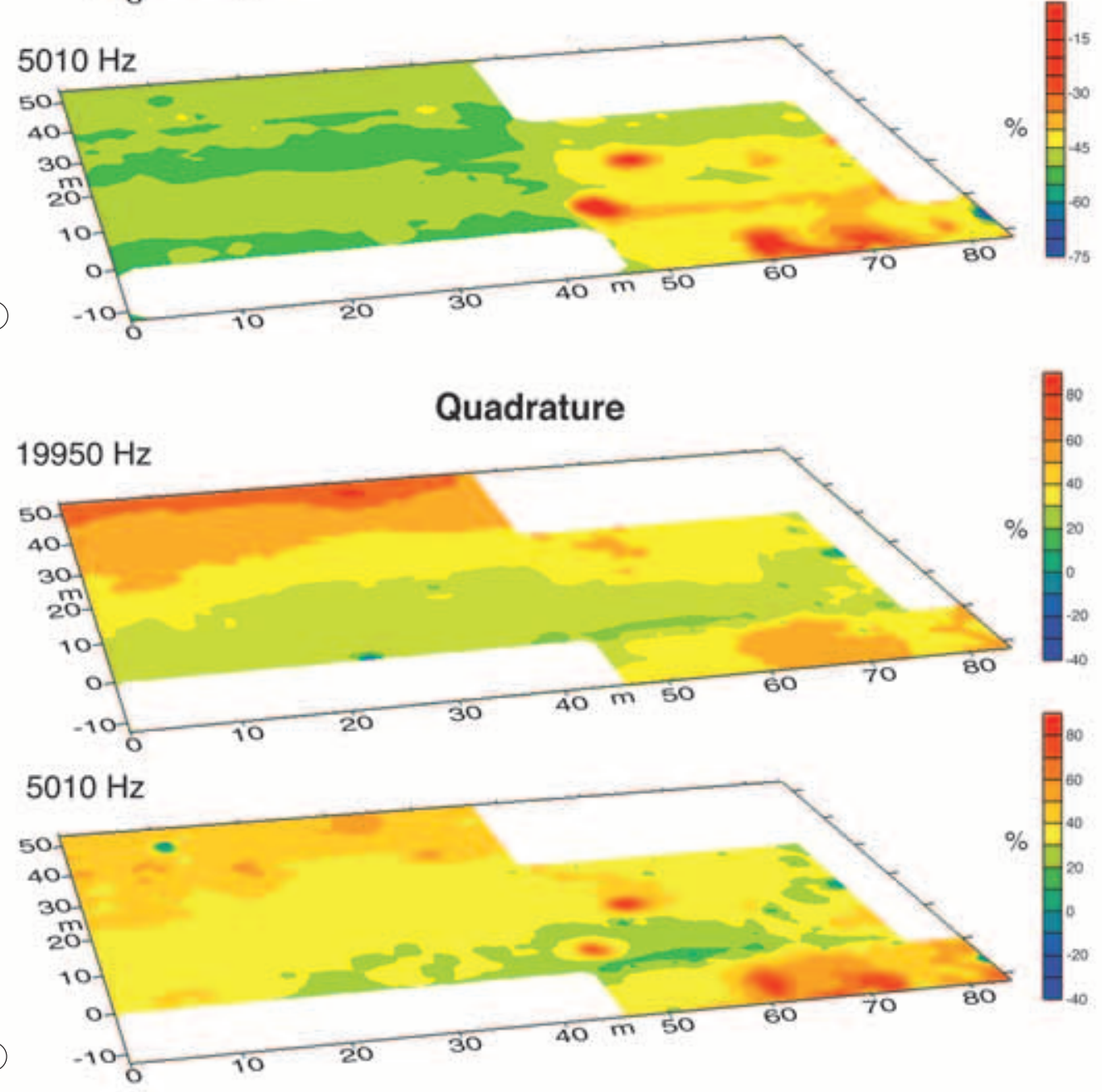

Fig. 5a,b. The in-phase (a) and quadrature (b) component anomaly maps at 19950 and $5010 \mathrm{~Hz}$ (expressed as a percentage intensity of the signal). 


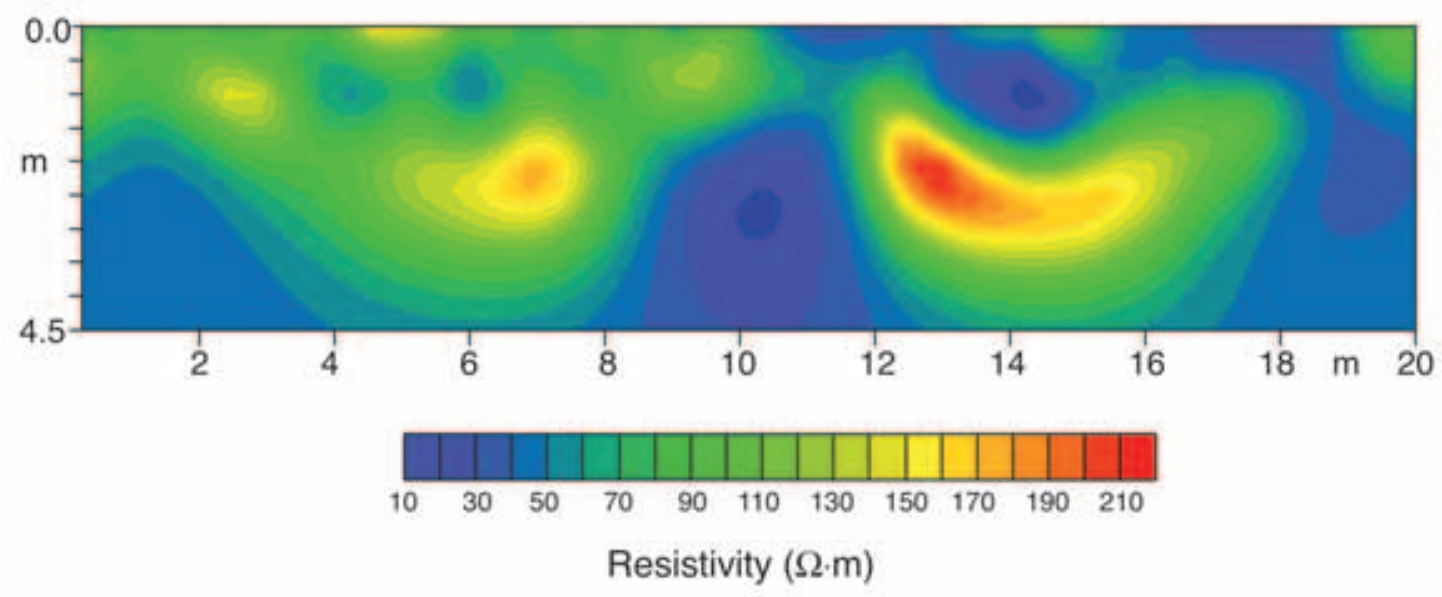

Fig. 6. Geoelectrical profile (along magnetic anomaly A, fig. 4a) showing a low resistivity area between two high resistivity sectors.

waste. The in-phase map (fig. 5a) roughly confirms the consideration described in the previous paragraph, showing anomalies corresponding to the area already identified by the magnetic surveys. The quadrature component map (fig. 5b) does not show additional anomalies besides those linked to the metallic target found through the in-phase map.

\section{Geoelectrical measurements}

Electrical imaging techniques have been broadly used in recent years, especially in environmental field where shallow soundings with high resolutions are required. In many geological situations, 2D imaging surveys can give useful results that are complementary to the information obtained by other geophysical methods. The dipole-dipole array is very sensitive to horizontal changes in resistivity, so it can be addressed to map vertical structures such as dykes and cavities, and buried objects. On the other hand, Wenner array can give useful information on vertical discontinuities, so the integration of the two methods can be very important to understand the subsoil structure (McNeill, 1994; Jordan and Costantini, 1995; Loke, 1999).
For a better characterization of the magnetic anomaly $\mathrm{A}$ (where the excavation was not made) a profile $23 \mathrm{~m}$ long oriented in the $\mathrm{S}-\mathrm{N}$ direction was performed using a resistivity meter IrisSyscal Kid. The profile was carried out by means of Wenner and dipole-dipole electrode arrays using 24 electrodes with $1 \mathrm{~m}$ spacing. Results are shown in fig. 6 where two resistivity regions $(150-200 \Omega \cdot \mathrm{m})$ and a low resistivity area of about $20 \Omega \cdot \mathrm{m}$ at a depth of about $1.5-4.0 \mathrm{~m}$ are recognizable. This effect can be explained if we assume that the low resistivity sector is related to the presence of many metallic bodies which determine a considerable lowering of the ground resistivity. The depth of this sector corresponds to the depth of the recovered metallic drums in other points of the quarry. These considerations suggest that probably there are many buried drums in the proximity of the magnetic anomaly A (disclosed by all geophysical techniques).

\section{Ground Penetrating Radar measurements}

Among the geophysical techniques used to study refuse disposal site, Ground Penetrating Radar (GPR) is not as widely used as the tech- 
niques described in the previous paragraphs. However, as is well known, the contribution of different kind of geophysical information can provide the best results. The advantage of GPR is that it provides better high lateral and vertical resolution of the investigated area in a very short time (Daniels, 1996; Orlando and Marchesi, 2001). Moreover, it does not depend on the particular nature of the searched target. In this case, the GPR measurements were done by a SIR10B GSSI equipped with a low frequency, portable lightweight antenna with very high penetration, the $300 \mathrm{MHz}$ Subecho Radarteam antenna. Such antenna is configured so that it can be suspended over the ground, handy especially in hard terrain.

Data were acquired in continuous mode using a trace acquisition rate of $40 \mathrm{scan} / \mathrm{s}$, along the profile shown in fig. 2. In order to eliminate noise, band pass filters were applied during the acquisition of the profiles. Acquired data have been migrated in order to eliminate the diffraction hyperbolas and a Hylbert transform was applied to disclose signal amplitude differences.

The GPR profile in fig. 2 was $26 \mathrm{~m}$ long and was carried out parallel to the geoelectrical profile described in the previous paragraph, across the large geomagnetic anomaly in the $\mathrm{S}$-E part of the area.

Results are shown in fig. 7. The two visible anomalies are about $12 \mathrm{~m}$ long and located at about $4 \mathrm{~m}$ from the beginning of the profile over the area identified previously by the magnetic and electromagnetic surveys (D in magnetic map, fig. 4a). The magnetic anomaly D (and also the corresponding anomaly from the gradiometric

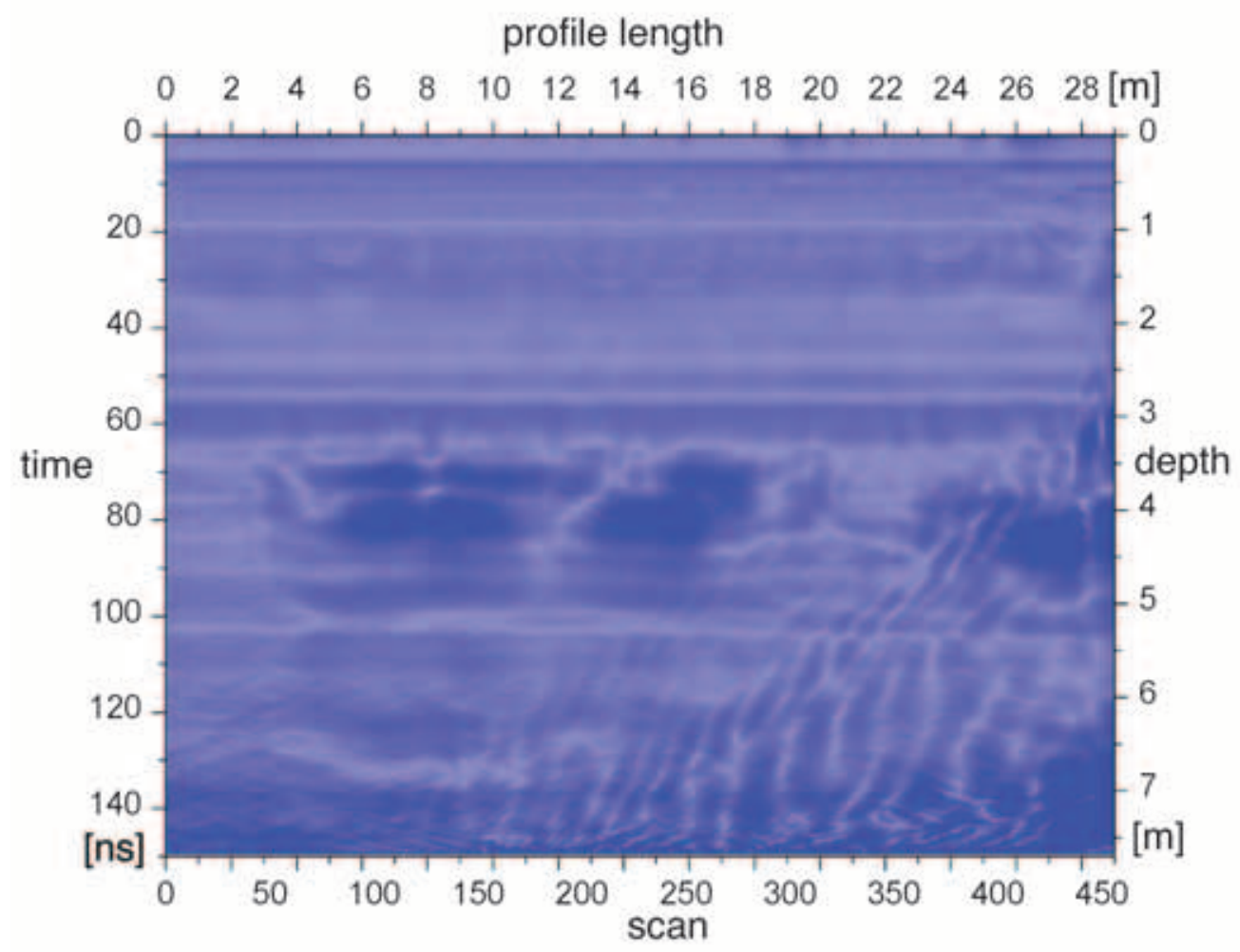

Fig. 7. Ground Penetrating Radar profile (along magnetic anomaly D, fig. 4a). Data were acquired in continuous mode using a trace acquisition rate of $40 \mathrm{scan} / \mathrm{s}$. Right side axis indicates the signal penetrating depth. 
and electromagnetic surveys) in this case was neither limited nor sharp. This point suggests that probably in the located zone there are two large heaps of heterogeneous buried rubbish mixed with ferromagnetic waste. If we assume a value of 8 or 9 for the relative dielectric constant of the ground, the depth of that waste is about 3-4 $\mathrm{m}$ as it was concluded by the previous considerations.

\section{Conclusions}

This paper reports the results of two ground magnetometric surveys and other geophysical methods performed in a tuff quarry in Riano Flaminio (North Rome). Suspected buried waste disposal of ferromagnetic targets was investigated on behalf of the Government Waste Recycling Committe. Detection and location of buried waste and steel drums were done through four different geophysical techniques.

The results of a preliminary magnetometric survey were validated at all sites: over 160 steel drums corresponding to the magnetic anomalies were found. After a preliminary reclaim, a new magnetic investigation followed by an electromagnetic survey was performed. Geoelectrical and GPR profiles were carried out on two sectors of the studied area in order to obtain a better characterization of the anomalies previously detected.

A good correlation between magnetic and electromagnetic anomalies emerges from the results presented. Moreover the electromagnetic anomalies are centred above the target giving an easier interpretation of its position.

These described surveys remarkably reduce the cost and time of investigations and the precise indication from the anomaly maps allows excavations to be undertaken only in limited sectors of the whole analysed area without introducing substantial modifications of the territory.

The combined use of these techniques with electrical tomography and GPR measurements determines both size and location of the detected underground refusals not only of metallic nature.

\section{Acknowledgements}

The authors wish to thank Prof. E. Boschi, President of INGV, for his continuous encouragement towards the development of the research in this field.

The authors are also very grateful to Drs. G. Morelli and S. Del Ghianda of the Geostudi Astier Ltd, Livorno, for their valuable support in the realization of this work.

\section{REFERENCES}

BREINER, S. (1973): Applications manual for portable magnetometers, Geometrics (395 Java Drive, Sunnyvale, California 94086), p. 70.

Coticchia, A., A. DE SANTis, A. Di Ponzio, G. Dominici, A. MELoni, M. PIEROZZI and M. SPERI (2001): Italian Magnetic Network and Geomagnetic Field Maps of Italy at year 2000.0, Boll. Geod. Sci. Affini, Anno LX, n. 4.

COCHRAN, J.R. and K.E. DALTON (1995): Using high-density magnetic and electromagnetic data for waste characterization, a case study, in Proceedings of the Symposium on the Application of Geophysics to Engineering and Environmental Problems, edited by R.S. BELL, Environmental and Engineering Geophysical Society, Orlando, Florida, p. 117

DAHLIN, T. and H. JEPPSSON (1995): Geophysical investigation of a waste deposit in Southern Sweden, in Proceedings of the Symposium on the Application of Geophysics to Engineering and Environmental Problems, edited by R.S. BELL, Environmental and Engineering Geophysical Society, Orlando, Florida, 97-105.

DANIELS, D.J. (1996): Surface-Penetrating Radar, Institution of Electrical Engineers, London, p. 300.

FOLEY, J.E. (1994): STOLMS ${ }^{\text {TM }}$ Magnetic survey at Sandia National Laboratory Technical area 2, in Proceedings of the Symposium on the Application of Geophysics to Engineering and Environmental Problems, March 27-31, 1994 Boston, Mass., edited by R.S. BELL and C.M. LEPPER, 895-907.

Gibson, P.J., P. LYLE and D.M. Gorge (1996): Environmental applications of magnetometry profiling, Environ. Geol., 27, 178-183.

Gilkeson, R.H., S.R. Gorin, R.F. Weston and D.E. LAYMON (1992): Application of magnetic and electromagnetic methods to metal detection, in Proceedings of the Symposium on the Application of Geophysics to Engineering and Environmental Problems, April 26-29, 1992, Oakbrook, Illinois, 309-328.

GSSI: GEM-300 Multi frequency electromagnetic profiler. Operating System.

JoRDANT, E. and D. COSTANTINI (1995): The use of NonInvasive electromagnetic (EM) techniques for focusing environmental investigations, in Ground Conductivity Meters for Environmental Site Evaluation (Geonics Limited, Ontario, Canada), 4-9. 
LOKE, M.H. (1999): Electrical imaging surveys for environmental and engineering studies, Technical Notes.

MARChetTI, M., M. CHIAPPINI and A. MELONI (1998): A test site for magnetic detection of buried steel drums, Ann. Geofis., 41 (3), 491-498.

MCNEILL, J.D. (1994): Principles and application of time domain electromagnetic techniques for resistivity sounding, Technical Note TN27 (Geonics Limited, Ontario, Canada).

ORLANDO, L. and E. MARCHESI (2001): Georadar as a tool to identify and characterize solid waste dump deposits, J. Applied Geophys., 48, 163-174.

PIERCE, D. and J. DE REAMER (1993): Geophysical investigation for buried drums: a case study, in Proceedings of
Symposium on the Application of Geophysics to Engineering and Environmental Problems, edited by R.S. BELL and C.M. LEPPER, Environmental and Engineering Geophysical Society, San Diego, California, 229-244.

Vogelsang, D. (1995): Environmental Geophysics. A Practical Guide (Springer-Verlag Eds), p. 173.

Won, I.J., D.A. KeISWETTER, G.R.A. FiELDS and L.C. SUTTON (1996): GEM-2: a new multifrequency electromagnetic sensor, JEEG, 1 (2), 129-137.

(received April 14, 2002;

accepted July 9, 2002) 